\title{
Comparison of visual pathology secondary to the light of polymerization. bibliographic review of the 5 main types of light in the market
}

\begin{abstract}
The use of light sources is a constant in dental practice. Many technical and instrumental materials base their properties on applying light at intensities superior to healthy ones for our ocular organ. 5 out of 10 work absences in the health sector is due to visual pathology. One of the main consequences of the technological advance achieved and the engineering of biomaterials was the achievement of lighting parameters that allow us to reduce time, techniques and improve the quality of our work. Thus, with the light of polymerizing in dentistry, the great disadvantages of the $30 \mathrm{~s}$ and $60 \mathrm{~s}$ on acrylic resins and their contraction in the cavitary walls were solved, thus heading towards one of the main milestones of contemporary dentistry, as were the discoveries of Bouncore and Bowen. For this and more, we must bear in mind the risk of exposure to which the health population, and especially the dental one, are exposed by routinely using light sources that exceed intensity and time of exposure to normal or healthy or at least, for which our eye has intrinsic defense methods.
\end{abstract}

Keywords: visual pathology,; photoreceptor, phototransduction, electromagnetic spectrum, ultraviolet light
Volume 7 Issue I - 2018

\author{
Marcos Moradas Estrada,' Beatriz Ivarez L \\ pez, ${ }^{2}$ Serrano 3 \\ 'Department of Surgery and Surgical Medical Specialties, \\ University of Oviedo, Spain \\ ${ }^{2}$ Tapia de Casariego, Spain \\ ${ }^{3}$ University Clinic of Dentistry, Spain
}

\begin{abstract}
Correspondence: Marcos Moradas Estrada,Associate Professor, Service of Conservative Dentistry and Dental Materials, Department of Surgery and Surgical Medical Specialties, University of Oviedo, Spain, Emailmarcosmords@gmail.com
\end{abstract}

Received: December 26, 2017 | Published: January II, 2018

\section{Introduction}

Light as a form of electromagnetic energy has a dual wave particle nature. When describing the effects of light absorbed by a photoreceptor, the behavior of light particles is more important. The portion of the electromagnetic spectrum that interacts with the eye is wider than the portion that is used for phototransduction. It includes wavelengths of ultraviolet light (100-400nm), visible light $(400-460 \mathrm{~nm})$ and infrared $(760-10000 \mathrm{~nm})$. Several subgroups of wavelengths can be classified for ultraviolet light: UVA (315-400nm), UVB $(260-315 \mathrm{~nm})$ and UVC $(100-260 \mathrm{~nm})$. In the same way three groups are described for infrared light. The visible light is called short length (blue), length (green) and long wavelength (red) according to the spectra of maximum absorption of the visual pigments of ocular knowings. ${ }^{1-12}$ Recent studies have evaluated the risk of constant exposure to light environmental irradiation, particularly dangerous for individuals over 40 years of age. UVA and UVB, which are not necessary for sight, induce the formation of cataracts. More importantly, short wavelength blue visible light (400-440nm) also represents a risk factor for the adult human retina and is also not essential for sight; concluding, according to these studies, that it would be important to be able to eliminate these wavelengths to reduce the risk of age-related macular degeneration. Relating the wavelengths with the multiple polymerization lamps, we have to know that they have different emission spectra, most of them remaining at wavelengths of $350-550 \mathrm{~nm}$ and with different light intensity. Halogen quartz-tungsten lamps, used and studied during the 1980s, had an intensity of around $300 \mathrm{~mW} / \mathrm{cm}^{2}$, while current high-voltage plasma (PAC) lamps and LED lamps have a much higher intensity higher, $3000 \mathrm{~mW} / \mathrm{cm}^{2}$ or more.

The greatest ocular risk associated with blue light occurs at approximately $440 \mathrm{~nm}$ (near the peak wavelength of many LED polymerization lamps), while the maximum risk in UV lengths is reached at $270 \mathrm{~nm}$. The blue light is absorbed by the retina. The use of polymerization lamps in conservative dentistry involves a total of several hours of exposure to said light throughout the day. On the other hand we must not ignore how depending on the angle of the light beam, the distance to the light source and the spectrum of the lamp, part of the radiation is absorbed by the target organ, part is dispersed to the neighboring structures and the rest is reflected. It is assumed that $10-30 \%$ of the emitted light is reflected towards the operator. ${ }^{13-30}$

\section{Potential risks of exposure to polymerization light}

Cell viability: The non-irradiated RPE cells grew adequately, however, irradiation inhibited growth. The difference between the nucleus of irradiated EPR cells with blue, green or white LED illumination and the non-irradiated ones was, statistically, very significant $(\mathrm{p}<0.01)$. The damage was highest in cells exposed to blue LED illumination, among which $99 \%$ of them became non-viable after exposure to blue light, although it is true that the decrease in cell viability did not It was presented in studies of exposure to blue light of shorter times (20 minutes) or it was presented to a lesser extent, demonstrating a factor to take into account as it is the time of exposure to radiation. ${ }^{31-35}$

Intracellular production of reactive oxygen species (ERO): Photochemical damage occurs when the incident radiation has a wavelength in the high energy range of the visible spectrum. An electron in an excited state can return to the inhibited state by dissipating the extra energy. One way to dissipate this energy is to break a bond in another molecule through a direct exchange of electrons or direct hydrogen exchange producing reactive oxygen species (ROS). A mechanism of cellular damage induced by light is, therefore, this oxidative process. The formation of ERO at the level of the EPR leads to cellular damage with the subsequent degeneration of the photoreceptors. A low production of reactive oxygen species was observed in EPR cells maintained in the dark. However, there is a significant increase in the ROS level after three light-dark cycles $(12 \mathrm{~h} / 12 \mathrm{~h})$ with blue light. ${ }^{36-42}$ 
Potential for mitochondrial membrane damage: No significant effect on the mitochondrial membrane potential was detected compared to the control cells for any of the different LED illuminations.

Damage to DNA: Significant DNA damage was observed for EPR cells exposed to light. The data in the fluorescence microscopes for all the irradiated EPR cells show an increased degradation of the nucleic acids compared to the control cells. The damage was shown to be maximum for cells exposed to blue LED illumination.

Cell apoptosis: The percentage of apoptotic cells increased in EPR cells exposed to light compared to EPR cells maintained in the dark. Cell death in the latter reached a frequency of $3.7 \%$. However, apoptosis occurred in $86 \%$ of the EPR cells exposed to blue light. In addition, the vulnerability of the eye towards irradiation increases in adult and elderly patients, due to the accumulation of endogenous products absorbing radiation in the EPR and to a decrease in the production of cellular antioxidants. ${ }^{43-55}$

Types of light and lamps and their comparative probability of damage: McCuskera et al. analyzed the maximum safety time for the ocular risks associated with 11 different polymerization lamps whose wavelengths and power per unit area were compared. For this, a spectroradiometer was used to measure the irradiation of the source within the spectral range of $400 \mathrm{~nm}$ to 550 at 7 predetermined distances of $2,10,20,30,40,50$ and $60 \mathrm{~cm}$ within which are considered most important $2 \mathrm{~cm}$ distance (direct exposure to light), 30 $\mathrm{cm}$ distance (represent the distance between light and operator's eye) and $60 \mathrm{~cm}$ distance (represent the distance between the light and the operator's eye)It is convenient to keep in mind two laws applicable in the situation that we want to analyze, and that are a fundamental part of optics as a science. The first is Beer - Lambert's law: it states that the totality of light that emanates from a light source can decrease due to three phenomena of physics, which are the following. The number of absorption materials in their trajectory, which is called concentration. This is the reason for the use of protective filters, as we will later study. Moreover, the distance that the light must cross from the light source to the determined body. We call this phenomenon, distance from the optical path, and it is part of the law that is cited below. And we have to know that probabilities that the photon of that particular wave amplitude can be absorbed by the material. This is the absorbency or also the extinction coefficient. ${ }^{56-62}$ The second law or law of Lambert, determines that the illumination produced by a light source on a surface is directly proportional to the intensity of the source and the cosine of the angle that forms the normal to the surface with the direction of the light rays and is inversely proportional to the square of the distance to said source. From the power per unit area $\left(\mathrm{mW} / \mathrm{cm}^{2}\right)$ measured at each distance and for each type of polymerization unit, different conclusions are obtained. Like the FusionLED lamp has the greatest intensity at all distances and in comparison with other lamps. In addition to this, luminous intensity of the LED lamps is greater than that produced by the halogen lamps and this, in turn, than the radiation of the plasma lamps. We cannot forget so important is the intensity drops significantly with distance. For example, the Fusion lamp presents a descent of $266.68 \mathrm{~mW} /$ $\mathrm{cm}^{2}$ (at $2 \mathrm{~cm}$ distance) up to $0.19 \mathrm{~mW} / \mathrm{cm}^{2}$ (at $60 \mathrm{~cm}$ distance). The maximum safety exposure time is the theoretical time that is assumed to be minimal for lesions on the ocular retina. The maximum safety exposure times for each of the polymerization lamps under test and for each of the seven distances are calculated using the guidelines published by the International Commission for the Protection against Non-Ionizing Radiation and are expressed in minutes. Checking the results with the studies of Labrie et al. who perform a similar study for distances of $30 \mathrm{~cm}, 50 \mathrm{~cm}$, and $100 \mathrm{~cm}$, we can see that the maximum exposure time of safety for a distance of $30 \mathrm{~cm}$ in high LED units power, such as Fusion, is $22.1+/-3.00$ minutes. This reflects the fact that the light intensity applied by polymerization lamps in dentistry is sufficiently powerful to cause serious damage to the transduction of the visual signal, if the appropriate filter device is omitted. The use of the light filter, well adapted to the emission spectrum of the lamp, can reduce the remaining irradiation to tolerable intensities and avoid the photochemical damage of the retina. Rassaei et al, exemplified in their study the utility of light filters using a luxometer to measure the light intensity of different sources emitting LED light at a distance of $30 \mathrm{~cm}$, among which are polymerization lamps and whose filters are those of their own of each brand or commercial house. In addition to these own filters, we consider the possibility of using protective glasses. Ordinary prescription glasses do not prevent the penetration of blue or UV light. Most manufacturers of polymerized lamps provide protective goggles, but this type of protection is currently not considered as usual in clinics. Both parties, dentist and patient, should wear protective goggles designed to filter out the damaging wavelengths of the polymerized lamp in particular. Some of these glasses filter the blue and UV light reducing the light transmission below $500 \mathrm{~nm}$ to less than $1 \%$.

An operator wearing appropriate eye protection can safely look at a lamp at a distance of $30 \mathrm{~cm}$ for a total of 10 minutes a day. Other proposed methods, of a more practical nature, when using the polymerization lamp are avoid looking at the light completely and we must cover the light with the reflecting face of a buccal mirror so that the excess blue light returns to the curing zone once again. It is recommended to verify the effectiveness of the filter, placing a small amount of composite resin on a sheet of paper, and placing the corresponding filter or lens on the resin. Then the polymerization unit must be placed on the other side of the filter and activated for 30 seconds. The resin should not polymerize if it is effective. However, with this procedure we have to take into account what we are checking, which is not more than the specific wavelength of polymerization of the composite used is being filtered, but we cannot know what are the exact limits of the range of lengths that we get extinguish. ${ }^{63-71}$

\section{Conclusion}

The negative effects of the blue light emitted by the polymerization lamps used in dental practice are shown by several studies, although they may be more or less probable or intense, or nonexistent, depending on the type of lamp used (wavelength and intensity of its radiation), time of exposure to the light emitted, type of light to which the operator is exposed (direct or reflected), distance to the light source, physical characteristics of the patient, technique used and methods of barrier or protection. Among these effects, the main one of a general nature and of concern is the increased risk of suffering agerelated macular degeneration prematurely, this being a consequence of different phenomena produced within the retinal pigment epithelium culture cells when These are exposed to blue light, such as: decrease in cell viability, intracellular production of reactive oxygen species (ROS), damage to cellular DNA and apoptosis in a certain percentage of cells. With the limitations of this review and taking into account the present conclusions, we should consider facing the harmful effects of the light of polymerizing in the dental cabinet.

\section{Acknowledgments}

None. 


\section{Conflicts of interest}

The author declares no conflicts of interest.

\section{References}

1. Medved L, Weisel JW. Recommendations for nomenclature on fibrinogen and fibrin. J Thromb Haemost. 2009;7(2):355-359.

2. Riedel T, Suttnar J, Brynda E, et al. Fibrinopeptides A and B release in the process of surface fibrin formation. Blood. 2011;117(5):1700-1706.

3. Moen JL, Gorkun OV, Weisel JW, et al. Recombinant BbetaArg14His fibrinogen implies participation of $\mathrm{N}$-terminus of Bbeta chain in desA fibrin polymerization. Blood. 2003;102(7):2466-2471.

4. Geer CB, Tripathy A, Schoenfisch MH, et al. Role of 'B-b' knob-hole interactions in fibrin binding to adsorbed fibrinogen. J Thromb Haemost. 2007;5(12):2344-2351.

5. Litvinov RI, Gorkun OV, Galanakis DK, et al. Polymerization of fibrin:Direct observation and quantification of individual B:b knob-hole interactions. Blood. 2007;109(1):130-138.

6. Okumura N, Terasawa F, Haneishi A, et al. B:b interactions are essential for polymerization of variant fibrinogens with impaired holes 'a'. $J$ Thromb Haemost. 2007;5(12):2352-2359.

7. Bowley SR, Lord ST. Fibrinogen variant BbetaD432A has normal polymerization but does not bind knob "B". Blood. 2009;113(18):44254430.

8. Yermolenko IS, Lishko VK, Ugarova TP, et al. High-resolution visualization of fibrinogen molecules and fibrin fibers with atomic force microscopy. Biomacromolecules. 2011;12(2):370-379.

9. Zhmurov A, Brown AE, Litvinov RI, et al. Mechanism of fibrin(ogen) forced unfolding. Structure. 2011;19(11):1615-1624.

10. Bowley SR, Okumura N, Lord ST. Impaired protofibril formation in fibrinogen gamma N308K is due to altered D:D and "A:a" interactions. Biochemistry. 2009;48(36):8656-8663.

11. Chernysh IN, Nagaswami C, Weisel JW. Visualization and identification of the structures formed during early stages of fibrin polymerization. Blood. 2011;117(17):4609-4614.

12. Medved' L, Ugarova T, Veklich Y, et al. Electron microscope investigation of the early stages of fibrin assembly. Twisted protofibrils and fibers. J Mol Biol. 1990;216(3):503-509.

13. Allan P, Uitte de Willige S, Abou-Saleh RH, et al. Evidence that fibrinogen $\gamma$ ' directly interferes with protofibril growth:implications for fibrin structure and clot stiffness. J Thromb Haemost. 2012;10(6):10721080 .

14. Cooper AV, Standeven KF, Ariëns RA. Fibrinogen gamma-chain splice variant gamma' alters fibrin formation and structure. Blood. 2003;102(2):535-540.

15. Gersh KC, Nagaswami C, Weisel JW, et al. The presence of gamma' chain impairs fibrin polymerization. Thromb Res. 2009;124(3):356-363.

16. Mullin JL, Gorkun OV, Lord ST. Decreased lateral aggregation of a variant recombinant fibrinogen provides insight into the polymerization mechanism. Biochemistry. 2000;39(32):9843-9849.

17. Hirota-Kawadobora M, Terasawa F, Yonekawa O, et al. Fibrinogens Kosai and Ogasa:Bbeta15Gly $\rightarrow$ Cys (GGT $\longrightarrow$ TGT) substitution associated with impairment of fibrinopeptide B release and lateral aggregation. J Thromb Haemost. 2003;1(2):275-283.

18. O'Brien ET, III, Falvo MR, Millard D, et al. Ultrathin self-assembled fibrin sheets. Proc Natl Acad Sci USA. 2008;105(49):19438-19443.

19. Tsurupa G, Mahid A, Veklich Y, et al. Structure, stability, and interaction of fibrin $\alpha \mathrm{C}$-domain polymers. Biochemistry. 2011;50(37):8028-8037.
20. Tsurupa G, Pechik I, Litvinov RI, et al. On the mechanism of $\alpha \mathrm{C}$ polymer formation in fibrin. Biochemistry. 2012;51(12):2526-2538.

21. Litvinov RI, Yakovlev S, Tsurupa G, et al. Direct evidence for specific interactions of the fibrinogen alphaC-domains with the central $\mathrm{E}$ region and with each other. Biochemistry. 2007;46(31):9133-9142.

22. Collet JP, Moen JL, Veklich YI, et al. The alphaC domains of fibrinogen affect the structure of the fibrin clot, its physical properties, and its susceptibility to fibrinolysis. Blood. 2005;106(12):3824-3830.

23. Ping L, Huang L, Cardinali B, et al. Substitution of the human $\alpha \mathrm{C}$ region with the analogous chicken domain generates a fibrinogen with severely impaired lateral aggregation: fibrin monomers assemble into protofibrils but protofibrils do not assemble into fibers. Biochemistry. 2011;50(42):9066-9075.

24. Kostelansky MS, Lounes KC, Ping LF, et al. Calcium-binding site beta 2, adjacent to the "b" polymerization site, modulates lateral aggregation of protofibrils during fibrin polymerization. Biochemistry. 2004;43(9):2475-2483.

25. Kostelansky MS, Lounes KC, Ping LF, et al. Probing the gamma2 calcium-binding site:studies with gammaD298,301A fibrinogen reveal changes in the gamma294-301 loop that alter the integrity of the "a" polymerization site. Biochemistry. 2007;46(17):5114-5123.

26. Dang CV, Shin CK, Bell WR, et al. Fibrinogen sialic acid residues are low affinity calcium-binding sites that influence fibrin assembly. $J$ Biol Chem. 1989;264(25):15104-15108.

27. Profumo A, Turci M, Damonte G, et al. Kinetics of fibrinopeptide release by thrombin as a function of $\mathrm{CaCl} 2$ concentration:different susceptibility of FPA and FPB and evidence for a fibrinogen isoform-specific effect at physiological Ca2+ concentration. Biochemistry. 2003;42(42):1233512348 .

28. Lounes KC, Ping L, Gorkun OV, et al. Analysis of engineered fibrinogen variants suggests that an additional site mediates platelet aggregation and that "B-b" interactions have a role in protofibril formation. Biochemistry. 2002;41(16):5291-5299.

29. Averett LE, Akhremitchev BB, Schoenfisch $\mathrm{MH}$, et al. Calcium dependence of fibrin nanomechanics:the $\gamma 1$ calcium mediates the unfolding of fibrinogen induced by force applied to the "A-a" bond Langmuir. 2010;26(18):14716-14722.

30. Park R, Ping L, Song J, Hong SY, et al. Fibrinogen residue $\gamma$ Ala341 is necessary for calcium binding and 'A-a' interactions. Thromb Haemost. 2012;107(5):875-883

31. Mosesson MW, DiOrio JP, Siebenlist KR, et al. Evidence for a second type of fibril branch point in fibrin polymer networks, the trimolecular junction. Blood. 1993;82(5):1517-1521.

32. Fogelson AL, Keener JP. Toward an understanding of fibrin branching structure. Phys Rev E Stat Nonlin Soft Matter Phys. 2010;81(5):051922.

33. Ryan EA, Mockros LF, Weisel JW, et al. Structural origins of fibrin clot rheology. Biophys J. 1999;77(5):2813-2826.

34. Chernysh IN, Weisel JW. Dynamic imaging of fibrin network formation correlated with other measures of polymerization. Blood. 2008;111(10):4854-4861.

35. Ferri F, Greco M, Arcòvito G, et al. Structure of fibrin gels studied by elastic light scattering techniques:dependence of fractal dimension, gel crossover length, fiber diameter, and fiber density on monomer concentration. Phys Rev E Stat Nonlin Soft Matter Phys. 2012;66(1):011913

36. Guthold M, Liu W, Stephens B, et al. Visualization and mechanical manipulations of individual fibrin fibers suggest that fiber cross section has fractal dimension 1.3. Biophys J. 2004;87(6):4226-4236. 
37. Evans PA, Hawkins K, Morris RH, et al. Gel point and fractal microstructure of incipient blood clots are significant new markers of hemostasis for healthy and anticoagulated blood. Blood. 2010;116(17):3341-3346.

38. Yeromonahos C, Polack B, Caton F. Nanostructure of the fibrin clot Biophys J. 2010;99(7):2018-2027.

39. Okada M, Blombäck B. Factors influencing fibrin gel structure studied by flow measurement. Ann N Y Acad Sci. 1983;408:233-253.

40. Spero RC, Sircar RK, Schubert R, et al. Nanoparticle diffusion measures bulk clot permeability. Biophys J. 2011;s101(4):943-950.

41. Weisel JW. Cross-linked gamma-chains in fibrin fibrils bridge transversely between strands: no. J Thromb Haemost. 2004;2(3):394 399.

42. Mosesson MW. Cross-linked gamma-chains in fibrin fibrils bridge 'transversely' between strands:yes. J Thromb Haemost. 2004;2(3):388393.

43. Guthold M, Carlisle C. Single fibrin fiber experiments sugges longitudinal rather than transverse cross-linking:reply to a rebuttal. $J$ Thromb Haemost. 2010;8(9):2090-2091.

44. Standeven KF, Carter AM, Grant PJ, et al. Functional analysis of fibrin gamma-chain cross-linking by activated factor XIII:determination of a cross-linking pattern that maximizes clot stiffness. Blood. 2007;110(3):902-907.

45. Lim BC, Ariëns RA, Carter AM, et al. Genetic regulation of fibrin structure and function:complex gene-environment interactions may modulate vascular risk. Lancet. 2003;361(9367):1424-1431.

46. Hoffman M. Alterations of fibrinogen structure in human disease Cardiovasc Hematol Agents Med Chem. 2008;6(3):206-211.

47. de Moerloose P, Neerman-Arbez M. Congenital fibrinogen disorders Semin Thromb Hemost. 2009;35(4):356-366.

48. Weisel JW, Nagaswami C. Computer modeling of fibrin polymerization kinetics correlated with electron microscope and turbidity observations:clot structure and assembly are kinetically controlled. Biophys J. 1992;63(1):111-128.

49. Konings J, Govers-Riemslag JW, Philippou H, et al. Factor XIIa regulates the structure of the fibrin clot independently of thrombin generation through direct interaction with fibrin. Blood. 2011;118(14):3942-3951.

50. Aleman MM, Gardiner C, Harrison P, et al. Differential contributions of monocyte- and platelet-derived microparticles towards thrombin generation and fibrin formation and stability. J Thromb Haemost. 2011;9(11):2251-2261.

51. Collet JP, Montalescot G, Lesty C, et al. A structural and dynamic investigation of the facilitating effect of glycoprotein IIb/IIIa inhibitors in dissolving platelet-rich clots. Circ Res. 2002;90(4):428-434.

52. Campbell RA, Overmyer KA, Bagnell CR, et al. Cellular procoagulan activity dictates clot structure and stability as a function of distance from the cell surface. Arterioscler Thromb Vasc Biol. 2008;28(12):2247-2254.

53. Mutch NJ, Engel R, Uitte de Willige S, et al. Polyphosphate modifies the fibrin network and down-regulates fibrinolysis by attenuating binding of tPA and plasminogen to fibrin. Blood. 2010;115(19):3980-3988.

54. Amelot AA, Tagzirt M, Ducouret G, et al. Platelet factor 4 (CXCL4) seals blood clots by altering the structure of fibrin. $J$ Biol Chem. 2007;282(1):710-720
55. Feghhi S, Sniadecki NJ. Mechanobiology of platelets:techniques to study the role of fluid flow and platelet retraction forces at the microand nano-scale. Int J Mol Sci. 201112(12):9009-9030.

56. Ovanesov MV, Ananyeva NM, Panteleev MA, et al. Initiation and propagation of coagulation from tissue factor-bearing cell monolayers to plasma: initiator cells do not regulate spatial growth rate. J Thromb Haemost. 2005;3(2):321-331.

57. Campbell RA, Overmyer KA, Selzman $\mathrm{CH}$, et al. Contributions of extravascular and intravascular cells to fibrin network formation, structure, and stability. Blood. 2009;114(23):4886-4896.

58. Gersh KC, Nagaswami C, Weisel JW. Fibrin network structure and clot mechanical properties are altered by incorporation of erythrocytes. Thromb Haemost. 2009;102(6):1169-1175.

59. Wolberg AS. Plasma and cellular contributions to fibrin network formation, structure and stability. Haemophilia. 2010;16(suppl):7-12.

60. Wolberg AS. Determinants of fibrin formation, structure, and function. Curr Opin Hematol. 2012;19(5):349-356.

61. Neeves KB, Illing DA, Diamond SL. Thrombin flux and wall shear rate regulate fibrin fiber deposition state during polymerization under flow. Biophys J. 2010;98(7):1344-1352.

62. Gersh KC, Edmondson KE, Weisel JW. Flow rate and fibrin fiber alignment. J Thromb Haemost. 2010;8(12):2826-2828.

63. Campbell RA, Aleman M, Gray LD, et al. Flow profoundly influences fibrin network structure: implications for fibrin formation and clot stability in haemostasis. Thromb Haemost. 2010;104(6):1281-1284.

64. Whittaker P, Przyklenk K. Fibrin architecture in clots:a quantitative polarized light microscopy analysis. Blood Cells Mol Dis. 2009;42(1):51-56

65. Varjú I, Sótonyi P, Machovich R, et al. Hindered dissolution of fibrin formed under mechanical stress. J Thromb Haemost. 2011;9(5):979986.

66. Colace TV, Muthard RW, Diamond SL. Thrombus growth and embolism on tissue factor-bearing collagen surfaces under flow: role of thrombin with and without fibrin. Arterioscler Thromb Vasc Biol. 2012;32(6):1466-1476.

67. Katoh M, Haage P, Wiethoff AJ, et al. Molecular magnetic resonance imaging of deep vein thrombosis using a fibrin-targeted contrast agent: a feasibility study. Invest Radiol. 2009;44(3):146-150.

68. He S, Bark N, Wang H, et al. Effects of acetylsalicylic acid on increase of fibrin network porosity and the consequent upregulation of fibrinolysis. J Cardiovasc Pharmacol. 2009;53(1):24-29.

69. Yeromonahos C, Marlu R, Polack B, et al. Antithrombin-independent effects of heparins on fibrin clot nanostructure. Arterioscler Thromb Vasc Biol. 201232(5):1320-1324.

70. Tehrani S, Mobarrez F, Antovic A, Santesson P, et al. Atorvastatin has antithrombotic effects in patients with type 1 diabetes and dyslipidemia. Thromb Res. 2010;126(3):e225-e231.

71. Parastatidis I, Thomson L, Burke A, et al. Fibrinogen beta-chain tyrosine nitration is a prothrombotic risk factor. $J$ Biol Chem 2008;283(49):33846-33853. 